\title{
Recomendaciones para la venta y promoción en el consultorio de tratamientos dermocosméticos
}

\author{
Judith Domínguez, Emma Verástegui, Oscar Arrieta, Rubén Burgos, Carlos Campillo, Miguel Á. Celis, \\ Manuel de la Llata, José Halabe, Sergio Islas, Luis Jasso, Alberto Lifshitz, Mucio Moreno, \\ Ricardo Plancarte, Alejandro Reyes-Sánchez, Guillermo Ruiz-Argüelles, Antonio Soda y Julio Sotelo* \\ Academia Nacional de Medicina, Comité de Ética y Transparencia en la Relación Médico-Industria (CETREMI), Ciudad de México, México
}

\section{Resumen}

Un capítulo novedoso es la atención y promoción por parte de médicos especialistas de aspectos relacionados con procedimientos estéticos, más que con la salud. La aspiración humana de la búsqueda de la belleza personal ha generado nuevos escenarios en la labor médica. El Comité de Ética y Transparencia en la Relación Médico Industria (CETREMI) de la Academia Nacional de México ha revisado esta circunstancia y emite recomendaciones tanto a los médicos como a los productores y potenciales consumidores de procedimientos estéticos.

PALABRAS CLAVE: Dermocosméticos. Venta en consultorios. Medicina estética.

\section{Recommendations for the sale and promotion of dermocosmetic treatments at the office}

\begin{abstract}
A novel chapter in current medical settings is the promotion and attention of esthetic aspects rather than health issues by health professionals. The human aspiration related to the search for personal beauty has generated new scenarios in medical practice. The Committee on Ethics and Transparency in the Physician-Industry Relationship (CETREMI) of the National Academy of Medicine of Mexico has analyzed this phenomenon and has issued recommendations directed both to medical professionals and to producers and potential consumers of esthetic procedures.
\end{abstract}

KEY WORDS: Dermocosmetic products. Sale at doctors' offices. Esthetics medicine.

Hay preocupación creciente en asociaciones académicas respecto a la relación entre profesionales de la salud y la industria farmacéutica y de tecnologías, las cuales influyen directamente en la prescripción a través de promocionales que, a su vez, pudiera inducir la indicación de un medicamento o tratamiento menos efectivo o en detrimento de la salud del paciente.
En los últimos años, dermatólogos y cirujanos plásticos venden productos dermocosméticos en sus consultorios y promueven distintos servicios estéticos, circunstancia que ha generado una cultura de belleza como sinónimo de aspiración a la perfección física, la cual puede ser opresiva y problemática.

Los productos dermocosméticos son una categoría de productos que generan amplias ganancias, algunos
Correspondencia:

*Julio Sotelo

E-mail: jsotelo@unam.mx

DOI: 10.24875/GMM.20005634

0016-3813/৫ 2020 Academia Nacional de Medicina de México, A.C. Publicado por Permanyer. Este es un artículo open access bajo la licencia CC BY-NC-ND (http://creativecommons.org/licenses/by-nc-nd/4.0/).
Fecha de recepción: 20-11-2019

Fecha de aceptación: 18-02-2020 
poseen mínima o nula efectividad y otros son claramente riesgosos.

La venta de medicamentos/cosméticos por parte de dermatólogos y cirujanos plásticos es una práctica habitual que facilita la compra en un lugar accesible de productos que probablemente no se encuentren cerca del lugar de residencia del paciente. Sin embargo, este tipo de ventas también facilita que se expendan productos sin etiquetado adecuado de los ingredientes, lo que dificulta la atención médica de presentarse efectos secundarios en los usuarios y obstruye el diagnóstico acertado.

En otro escenario, los laboratorios venden sus productos únicamente al médico, para que este a su vez los venda al paciente, lo cual significa que el producto no pasa por el control regulatorio en farmacias.

Las naturales limitaciones en conocimiento médico del paciente lo llevan a buscar opciones de procedimientos cosméticos en clínicas, algunas reconocidas académicamente y otras no. Esta falta de información hace que numerosas personas compren en consultorios o estéticas productos "milagro" o que se realicen procedimientos innecesarios, en busca de mejoría estética como sinónimo de salud. Si bien es importante recordar que, de acuerdo con la definición de salud de la Organización de la Salud, la conformidad personal con los aspectos estéticos del propio cuerpo forma parte de la salud.

Por lo anterior, el Comité de Ética y Transparencia en la Relación Médico-Industria (CETREMI) emite las siguientes recomendaciones:

a) Para el médico que realiza procedimientos estéticos.

1. El procedimiento en cuestión no deberá ser ofrecido sin que el paciente lo solicite; de ser así, deberá proporcionar toda la información adecuada y detallada sobre los riesgos y beneficios potenciales del procedimiento cosmético que se solicita.

2. El médico puede tener a la venta productos dermocosméticos, siempre y cuando ofrezca al paciente la opción de adquirirlos en sitios autorizados por las agencias regulatorias (clínicas o farmacias).

3. Los productos manufacturados domésticamente y sin detalles explícitos de sus ingredientes y formulación no deberán ser vendidos en consultorios o clínicas.

4. Recomendamos que los médicos se abstengan de participar en operaciones comerciales.
5. El médico que atiende asuntos dermocosméticos tiene la obligación de estar certificado por el consejo de su especialidad y mostrar esta información profesional en la receta y exhibirla en su consultorio o clínica.

b) Para el paciente.

1. Puede o no someterse a tratamientos de belleza, siempre y cuando él lo solicite y tenga toda la información científica adecuada.

2. Debe solicitar la información detallada sobre el procedimiento, sus beneficios y posibles complicaciones.

3. Debe constatar que el médico que realizará el procedimiento tenga registro de salubridad y cédula profesional, así como certificado de consejo académico respectivo y las autorizaciones necesarias.

c) Para la industria farmacéutica.

1. Los productos dermocosméticos deberán estar disponibles en farmacias establecidas y no deberían ser vendidos directamente al médico, para que este no se convierta en el vendedor de sus productos.

2. Los productos y tecnología siempre deberán estar respaldados por evidencia real de sus beneficios y riesgos y disponer de los permisos sanitarios correspondientes.

3. La promoción de los productos deberá llevarse a cabo con personal académicamente calificado y con capacidad profesional certificada.

\section{Financiamiento}

La presente investigación no recibió ninguna beca de agencias de los sectores público, comercial o sin ánimo de lucro.

\section{Responsabilidades éticas}

Protección de personas y animales. Los autores declaran que para esta investigación no se realizaron experimentos en seres humanos ni en animales.

Confidencialidad de los datos. Los autores declaran que han seguido los protocolos de su centro de trabajo en cuanto a la publicación de datos de pacientes.

Derecho a la privacidad y consentimiento informado. Los autores declaran que en este artículo no aparecen datos de pacientes. 